\title{
Correction to: Evaluation of the water resource plans in Turkey based on sustainable water management principles
}

\section{Sahar Pouya ${ }^{1}\left[\right.$ ] $\cdot$ Handan Turkoglu ${ }^{2}$}

Published online: 16 February 2021

○) Springer Nature Switzerland AG 2021

\section{Correction to:}

Sustainable Water Resources Management (2020) 6:91 https://doi.org/10.1007/s40899-020-00444-1

Figure 2 is corrected through this correction.

"Büyükçekmece Water basin" on the wrong map is replaced with "Elmalı Dam-lakes" on the corrected one.

Elmalı Dam-lakes on the wrong map is replaced with "Büyükçekmece Water basin" on the corrected one.

Gördes Dam-lake basin on the wrong map is replaced with Melen Dam-lake on the corrected one.

Melen Dam-lake basin on the wrong map is replaced with Gördes Dam-lake on the corrected one.
Publisher's Note Springer Nature remains neutral with regard to jurisdictional claims in published maps and institutional affiliations.

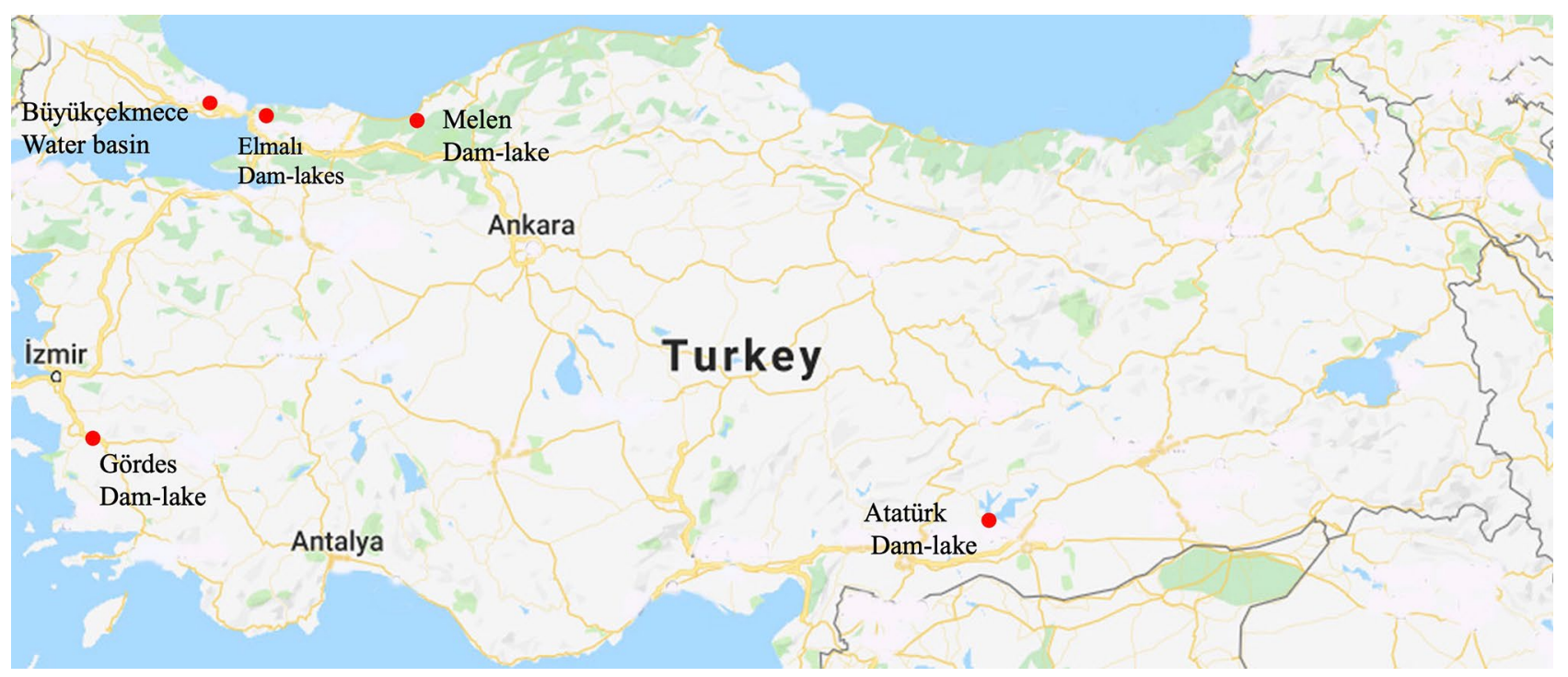

The original article can be found online at https://doi.org/10.1007/ s40899-020-00444-1.

Sahar Pouya pouya@itu.edu.tr

Handan Turkoglu turkoglu@itu.edu.tr
1 Department of Urban and Regional Planning, Graduate School of Science Engineering and Technology, Istanbul Technical University, Istanbul, Turkey

2 Department of Urban and Regional Planning, Architecture Faculty, Istanbul Technical University, Istanbul, Turkey 